\title{
Prognostic value of urokinase plasminogen activator system in non-small cell lung cancer: A systematic review and meta-analysis
}

\author{
JIA-JU LU ${ }^{1}$, HONG GUO ${ }^{2}$, BO GAO ${ }^{1}$, YUN ZHANG ${ }^{1}$, QING-LING LIN ${ }^{2}$, \\ JIANG SHI ${ }^{1}$, JING-JING LIU ${ }^{1}$ and JIAN LIU ${ }^{2}$ \\ ${ }^{1}$ The First Clinical Medical College; ${ }^{2}$ The First Hospital, Lanzhou University, Lanzhou, Lanzhou 730000, P.R. China
}

Received March 22, 2017; Accepted October 26, 2017

DOI: $10.3892 / \mathrm{mco} .2017 .1484$

\begin{abstract}
Current relevant research suggests there are significant differences between the expression of the urokinase plasminogen activator (uPA) system in cancer tissues and in normal tissues. However, the potential effectiveness of the uPA system as a prognostic biomarker of non-small cell lung cancer (NSCLC) remains unclear. In the present study, a systematic review and meta-analysis were performed to evaluate the relevance of the uPA system in the prognosis of patients with NSCLC. Using the PubMed, EMBASE, Web of Science and Cochrane Library databases, data from relevant academic journal articles were extracted and subjected to analysis. Associations between expression profiles pertaining to the UPA system and the overall survival (OS) of patients with NSCLC were analyzed. The study incorporated data from 11 independent journal articles and these reports included a total of 937 patients with NSCLC. The meta-analysis results revealed that increased expression of urokinase plasminogen activator (uPA) and PA inhibitor type 1 (PAI-1) exhibited no significant association with poor OS [hazard ratio $(\mathrm{HR})-\mathrm{uPA}=1.07$ (0.87-1.31), $\mathrm{P}=0.53$; HR-PAI-1=1.02 (0.63-1.65), $\mathrm{P}=0.94]$. Similarly, reduced expression of PAI type 2 (PAI-2) did not significantly correlate with poor OS [HR-PAI-2 $=1.58$ (0.64-3.90); $\mathrm{P}=0.32$ ]. Notably, however, a significant association was observed between increased expression levels of uPA receptor (uPAR) and poor OS for NSCLC [HR-uPAR=1.50 (1.04-2.15); $\mathrm{P}=0.03]$. Therefore, the expression of $\mathrm{UPAR}$ in the UPA system of patients with NSCLC could be used as a novel clinical biomarker to evaluate the prognosis of NSCLC. The utilization of this biomarker may provide a platform for the further development of targeted drugs for the treatment of NSCLC.
\end{abstract}

Correspondence to: Dr Jian Liu, The First Hospital of Lanzhou University, 1 Donggang West Road, Lanzhou, Lanzhou 730000, P.R. China

E-mail:medecinliu@sina.com

Key words: uPA system, non-small cell lung cancer, overall survival, hazard ratio, meta-analysis

\section{Introduction}

Over the past 50 years, the worldwide incidence of lung cancer has significantly increased. In developed countries and large cities, lung cancer has become the most common type of cancer among males. In many countries, the number of mortalities due to lung cancer has surpassed the combined numbers from prostate cancer, breast cancer and gastrointestinal tumors $(1,2)$. The majority of patients with lung cancer are males over the age of 40; however, the number of female patients has also increased significantly in recent years. Typically, lung cancer is divided into two categories: Small cell lung cancer (SCLC) and non-SCLC (NSCLC). As SCLC is distinct from NSCLC with respect to its biological behavior, treatment, prognosis and other features, the present study focused on the associations between NSCLC prognosis and the uPA system. Although there has been considerable progress in the diagnosis and treatment of NSCLC in recent years, the majority of cases are diagnosed only at an advanced stage. Consequently, the 5-year survival rate for NSCLC is $~ 15 \%$ (3). The invasion and distant metastasis of NSCLC cells are the most important biological characteristics of malignant lung tumors; these phenomena result in the associated low survival rates of patients with NSCLC (4). Thus, a biomarker that facilitates the recognition of NSCLC invasion, metastasis and prognosis would aid thoracic surgeons in treatment regimen selection.

The uPA system includes urokinase plasminogen activator (uPA), uPA receptor (UPAR), and two inhibitors, PA inhibitor type 1 (PAI-1) and PAI type 2 (PAI-2). uPA can be produced by fibroblasts, monocytes, neutrophils, epithelial cells and tumor cells, among others. The specific receptor for uPA, uPAR, is a multifunctional receptor able to mediate the activation of PA, signaling pathways, cell adhesion and metastasis following the binding of uPA (5-8). uPAR is composed of 283 amino acid residues and has a molecular weight of 55-60 kDa. The receptor is a glycoprotein that is anchored to the membrane by a glycosylated phosphatidylinositol. This glycoprotein regulates proteolysis at the invading edge of tumors (9). uPAR serves a critical function in cancer progression through its interaction with integrins and vitronectin, and its role as a regulator of angiogenesis. PAI-1 and PAI-2 are specific inhibitors of UPA; PAI-1 exhibits increased activity in comparison with PAI-2, and is the primary inhibitor of UPA. PAI-1 is predominantly 
produced by blood platelets, epithelial cells, granulosa cells and tumor cells. PAI-2 is produced by tumor cells, trophoblasts and monocytes, and exhibits increased expression levels in the plasma of pregnant females. PAI combines with uPA (1:1 ratio) to generate a stable complex that inhibits uPA-mediated activities (10).

Numerous studies have indicated that the expression levels of uPA, uPAR, PAI-1 and PAI-2 significantly correlate with poor prognoses (11-13). In the present study, recent and relevant literature regarding associations between the uPA system and NSCLC were analyzed, and inconsistencies in the conclusions were revealed. Certain articles reported that high uPAR expression levels correlate with poor overall survival (OS), while other articles revealed no such association. Thus, a meta-analysis on the current and available research was conducted, in order to evaluate the associations between protein expression in the uPA system and the prognosis of patients with NSCLC.

\section{Data collection methods}

Publication search. The PubMed (https://www.ncbi.nlm.nih. gov/pubmed), EMBASE (www.embase.com), Web of Science (http://isiknowledge.com) and Cochrane Library (http://www. cochranelibrary.com) databases were used to search for academic articles written in the English language, with the most recent search conducted on June 30, 2016. The search criteria consisted of combinations of medical subheadings and keywords, including 'lung cancer', 'pulmonary neoplasm', 'uPA', 'uPAR', 'PAI-1', 'PAI-2' and 'uPA system'. Using Endnote X7 software (Clarivate Analytics, London, UK) the two authors independently removed and filtered the duplicates.

Inclusion and exclusion criteria. Regarding the meta-analysis, the inclusion criteria were as follows: 1) The diagnosis histological subtype was either squamous cell carcinoma (SCC), adenocarcinoma (AC), large cell lung cancer (LCC), bronchioalveolar carcinoma (BAC) or another rare NSCLC subtypes (NSCLC mix, nos); 2) the patients were $>18$ years of age; 3) the research focused on the expression of uPA, uPAR, PAI-1 and PAI-2 and the associated patient prognosis. The following exclusion criteria were applied: 1) Literature regarding the expression of proteins in the uPA system in SCLC; 2) the detection of uPA system proteins in the patient's circulation, effusion or cerebrospinal fluid; 3) reports that lacked relevant outcomes or Kaplan-Meier survival curve data, or studies without available or extractable data; 4) abstracts only and reviews; 5) literature not published in the English language; 6) duplicate articles; 7) animal and cell research. In total, 2,403 papers were searched, of which 11 articles (937 patients) were included in this meta-analysis.

Data extraction. The two authors independently retrieved the relevant data from the literature. The data included the following: the name of the first author; the date of publication, the country and region; the total number of patients included in the literature and their pathological classifications; the hazard ratios (HRs) and $95 \%$ confidence intervals (CIs) pertaining to the OS and the differential expression of UPA, uPAR, PAI-1 and PAI-2 in patients with NSCLC. For articles that only provided the Kaplan-Meier survival curve (K-M survival curve), the data were gathered from the K-M survival curve, which was obtained using the graph data extraction software Engauge Digitizer (version 4.1; http://markummitchell.github. io/engauge-digitizer) through continuous point gathering. The HR values were calculated using the Microsoft Office Excel (version 2013) (Microsoft Corporation; Redmond, WA, USA) program provided by Tierney et al (14), and finally the data were converted from the HR values to $\mathrm{Ln}$ (HR) and se [ln (HR)] for statistical analysis using RevMan (version 5.3; http://community.cochrane.org/tools/review-production-tools) (15). Any discrepancies were resolved following discussion or through consultation with a third party.

Statistical analysis. A chi-squared-based Q-test was used to examine the assumption of heterogeneity. An $\mathrm{I}^{2}$ value was used to describe the heterogeneity between multiple studies. When the $\mathrm{I}^{2}$ value was $\geq 50 \%$, it indicated that there was a relatively large degree of inter-study heterogeneity, and thus, a random effects model was required to calculate the combined $\mathrm{HR}$ value pertaining to each study. Otherwise, a fixed effects model was used. OS was evaluated by using pooled Cox proportional HRs and 95\% CIs. Statistical analyses, forest plots and funnel plots were performed and created using RevMan software (version 5.3). $\mathrm{P}<0.05$ was considered to indicate a statistically significant difference.

\section{Results}

Nature of the literature used in the meta-analysis. The current meta-analysis follows the relevant criteria of the Preferred Reporting Items for Systemic Reviews and Meta-Analyses statement (16). According to retrieval strategies, the present meta-analysis retrieved a total of 2,403 articles. Using Endnote X7 software, 821 duplicate articles were removed. A further 179 articles regarding animal research, 369 articles regarding cell research and 987 irrelevant articles were removed once the respective titles and abstracts were read and analyzed. Following reading of the full text of the remaining 47 articles, 36 were removed in accordance with the selection criteria, leaving 11 articles (17-27) (937 patients) to be included in the meta-analysis. The retrieval process is presented in Fig. 1. Of the 11 articles selected, there were 8 associated with SCC, 10 associated with AC, 6 associated with LCC and 2 associated with mixed-type NSCLC and NSCLC not otherwise specified. All of the relevant details of the articles included are listed in Table I. In the meta-analysis, OS was set as the outcome of the final observation.

Indicator expression discrepancies in the UPA system, and their association with $O S$. In this meta-analysis, a cohort that exhibited relatively high heterogeneity was evaluated for associations between PAI-1, PAI-2 and uPAR expression and the associated OS values. Thus, the random effects model was used to analyze the association between expression of PAI-1, PAI-2, and UPAR and OS, while a fixed effects model was used for uPA. Among the 11 articles that were used in this meta-analysis, eight investigated the association between PAI-1 expression and OS, two investigated PAI-2, six investigated uPA and seven investigated uPAR. The 


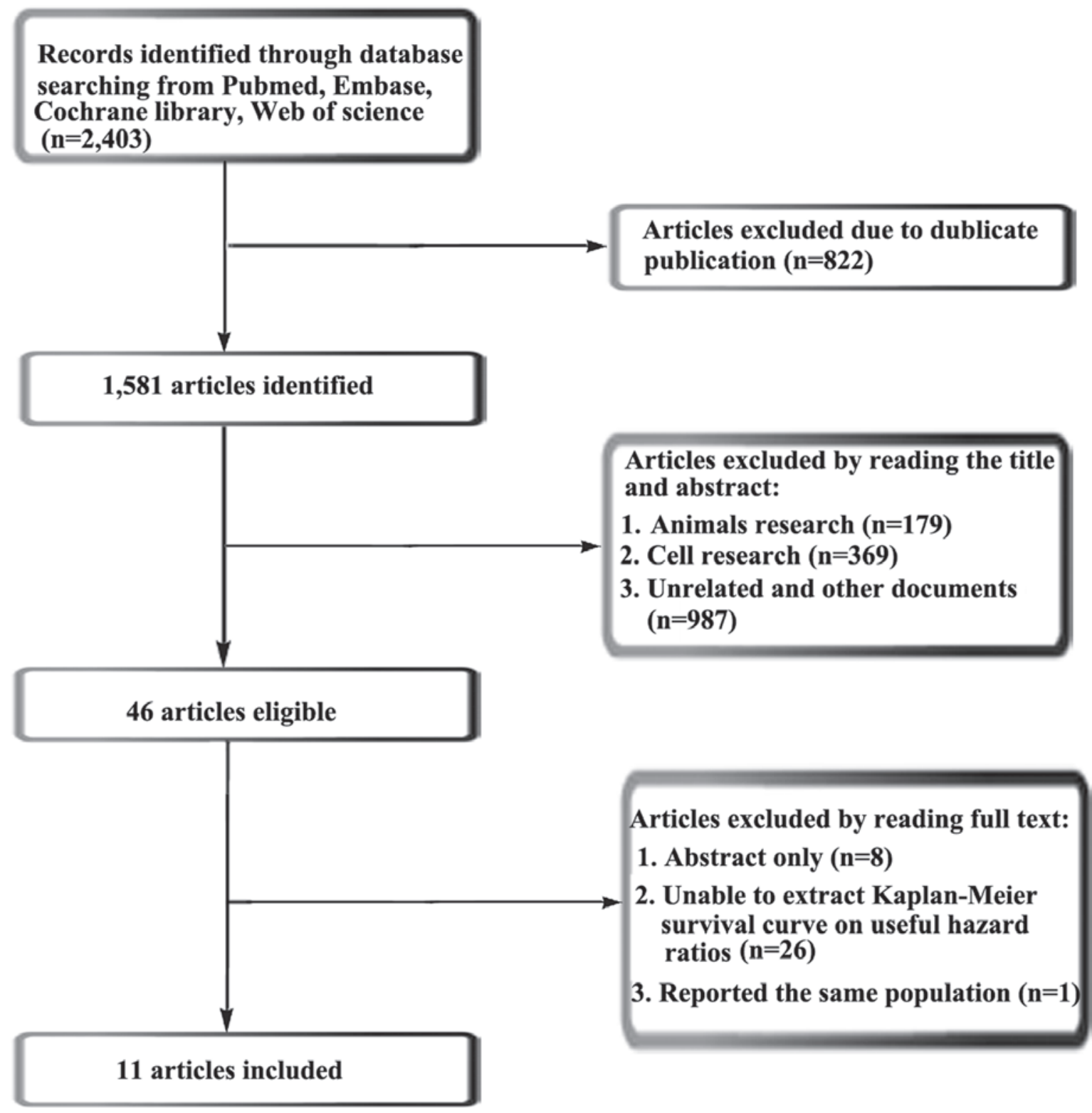

Figure 1. A flow chart indicating the selection process of studies for inclusion in meta-analysis.

results of the meta-analysis revealed that increased expression of uPA (Fig. 2) and PAI-1 (Fig. 3) and low expression of PAI-2 (Fig. 4) did not significantly correlate with OS (uPA: $\mathrm{HR}=1.07,95 \% \mathrm{CI}=0.87-1.31, \mathrm{P}=0.53$; PAI-1: $\mathrm{HR}=1.02,95 \%$ $\mathrm{CI}=0.63-1.65, \mathrm{P}=0.94$; PAI-2: $\mathrm{HR}=1.58$, 95\% CI=0.64-3.90, $\mathrm{P}=0.32)$. Increased uPAR expression was associated with poor OS $(\mathrm{HR}=1.50,95 \% \mathrm{CI}=1.04-2.15, \mathrm{P}=0.03$; Fig. 5), indicating that UPAR is an independent prognostic factor in NSCLC. No significant publication bias of OS (UPAR) was detected using the funnel plot (Fig. 6).

\section{Discussion}

The present meta-analysis investigated the associations between OS and UPA, uPAR, PAI-1 and PAI-2 expression in patients with NSCLC using English language peer-reviewed scientific articles. Following reading of the full journal articles selected from the databases, certain discrepancies were identified in the conclusions. Thus, to more accurately evaluate the associations between the expression of proteins in the UPA system and the prognosis of patients with NSCLC, a total of 11 articles were selected to conduct a meta-analysis of the included 937 patients. Results of the meta-analysis indicated that the expression levels of uPA, PAI-1 and PAI-2 had no significant association with poor OS in patients with NSCLC. Conversely, high expression of UPAR did significantly correlate with poor OS for patients with NSCLC.

UPAR is a $55-60 \mathrm{kDa}$ glycoprotein that belongs to the Ly-6 family (28). The gene encoding for this receptor is located on chromosome 19q13.2, and is composed of seven exons separated by six introns (29). The binding of uPA to uPAR orchestrates various signaling molecules that mediate a number of biological responses, including proliferation, migration, invasion, angiogenesis and metastasis (30). Cancer cells can produce UPA and UPAR; uPA binds to UPAR on the surface of these cells, activating the proteolytic domain of 
Table I. Features of the included studies.

\begin{tabular}{|c|c|c|c|c|c|c|c|}
\hline $\begin{array}{l}\text { First } \\
\text { author }\end{array}$ & Country & $\begin{array}{l}\text { Publication } \\
\text { time }\end{array}$ & $\mathrm{N}$ & Histological type & Indicators & $\begin{array}{l}\text { Survival } \\
\text { analysis }\end{array}$ & (Refs.) \\
\hline Almasi & Denmark & 2005 & 63 & SCC & uPAR & OS & (17) \\
\hline Almasi & Denmark & 2009 & 32 & $\mathrm{SCC}, \mathrm{AC}, \mathrm{LCC}$ & uPAR & OS & (18) \\
\hline Almasi & Denmark & 2011 & 171 & $\begin{array}{l}\text { SCC, AC, LCC, } \\
\text { BAC NSCLC } \\
\text { mix, nos }\end{array}$ & uPAR & OS & (19) \\
\hline Blumenschein & USA & 2011 & 54 & $\mathrm{SCC}, \mathrm{AC}$ & uPA, PAI-1, uPAR & OS, PFS & (20) \\
\hline $\mathrm{Su}$ & Taiwan & 2015 & 98 & $\mathrm{SCC}, \mathrm{AC}, \mathrm{LCC}$ & uPA, PAI-1, PAI-2, uPAR & OS, DFS & $(21)$ \\
\hline Pappot & Denmark & 1999 & 54 & $\mathrm{AC}$ & PAI-1, uPAR & OS & (22) \\
\hline Offersen & Denmark & 2007 & 118 & $\mathrm{SCC}, \mathrm{AC}, \mathrm{LCC}$ & uPA, PAI-1 & OS & (23) \\
\hline Pappot & Denmark & 2006 & 99 & $\mathrm{AC}$ & uPA, PAI-1 & OS & $(24)$ \\
\hline Pedersen & Denmark & 1994 & 54 & $\mathrm{AC}$ & uPA, PAI-1 & OS & $(25)$ \\
\hline Salden & Netherlands & 2000 & 88 & $\begin{array}{l}\text { SCC, AC, LCC, } \\
\text { NSCLC mix }\end{array}$ & uPA, PAI-1, PAI-2, uPAR & OS & $(26)$ \\
\hline Werle & Germany & 2004 & 106 & $\mathrm{SCC}, \mathrm{AC}, \mathrm{LCC}$ & PAI-1 & OS & (27) \\
\hline
\end{tabular}

SCC, squamous cell carcinoma; AC, adenocarcinoma; LCC, large cell carcinoma; BAC, bronchioalveolar carcinoma; NSCLC mix, nos, carcinoma indicating components of more than one histological subtype of NSCLC and NSCLC not otherwise specified; OS, overall survival; DFS, disease-free survival.

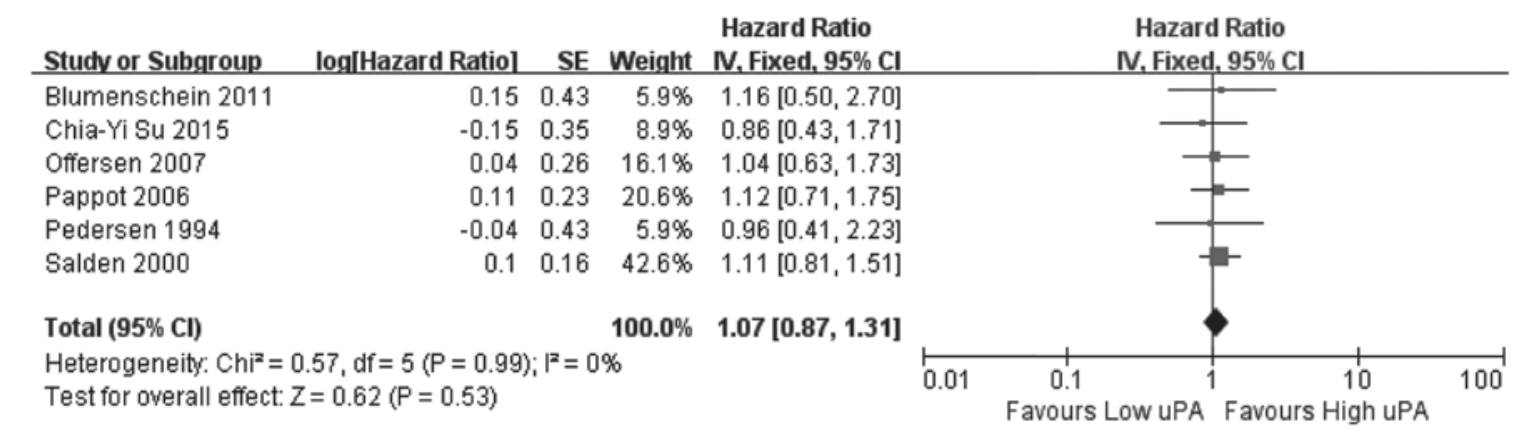

Figure 2. Forest plot: uPA expression is associated with OS. uPA, urokinase plasminogen activator; OS, overall survival; HR, hazard ratio; CI, confidence interval.

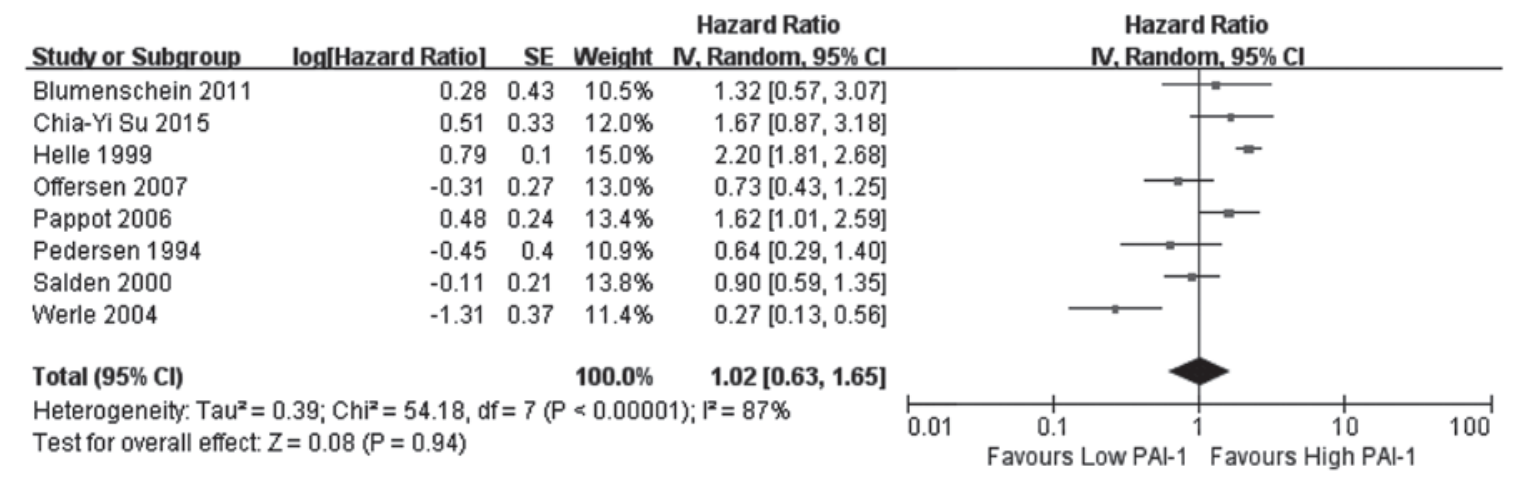

Figure 3. Forest plot: PAI-1 expression is associated with OS. PAI-1, plasminogen activator inhibitor type 1; OS, overall survival; HR, hazard ratio; CI, confidence interval.

uPA, as well as stimulating intracellular signals leading to the upregulation of UPAR and uPA itself. The UPA-uPAR complex can subsequently facilitate the transformation of plasminogen to plasmin, which can then cause extracellular matrix degradation (31). These events confer tumor cells with the ability to degrade the components of the surrounding extracellular 


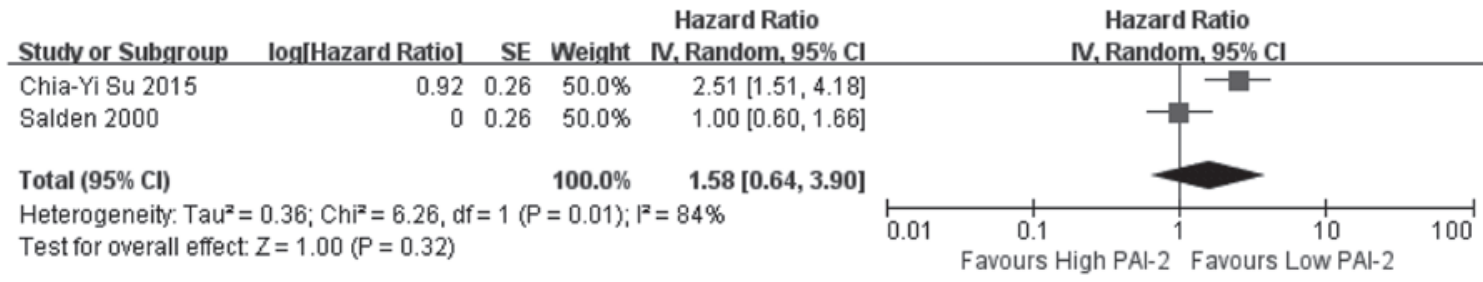

Figure 4. Forest plot: PAI-2 expression is associated with OS. PAI-2, plasminogen activator inhibitor type 2; OS, overall survival; HR, hazard ratio; CI, confidence interval.

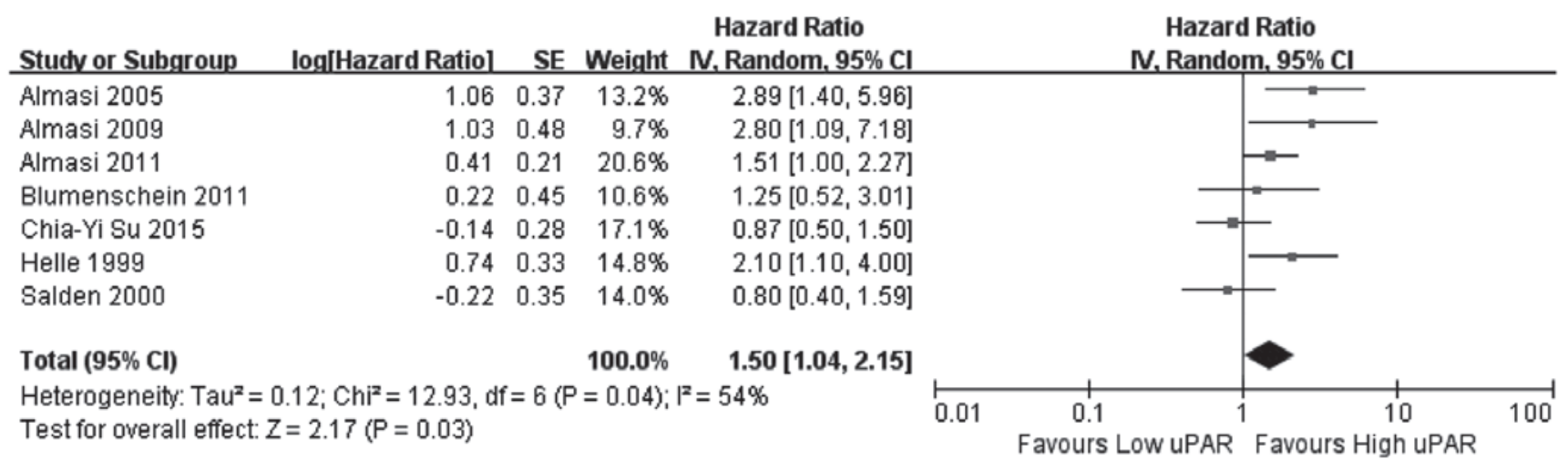

Figure 5. Forest plot: uPAR expression is associated with OS. uPAR, urokinase plasminogen activator receptor; OS, overall survival; HR, hazard ratio; CI, confidence interval.

matrix, thus contributing to tumor cell invasion and metastasis, resulting in poor OS.

The interaction between uPA and UPAR also results in the release of signaling molecules that stimulate cell proliferation/survival and the expression of tumor-promoting genes (32). Consequently, the binding of uPAR by uPA assists in the process of tumor development. Indeed, an inhibitory peptide that prevents UPA-uPAR interaction has demonstrated promise in prolonging patient survival during the early stages of a clinical trial (33). Furthermore, recent studies have identified significant differences in the expression of UPAR between cancer tissues and normal tissues (34). In general, the importance of the UPAR co-receptor in facilitating the tumor-promoting effects of UPAR suggests that disruption of the interactions between UPAR and its functional partners may be a potentially crucial strategy for the development of anticancer therapeutic agents.

Some limitations need to be acknowledged for the current meta-analysis. First, the sample size included was relatively small (937 patients with NSCLC). Second, the various histological types of NSCLC, including squamous cell carcinoma and adenocarcinoma, exhibit stereotypical biological characteristics, which create a certain level of bias. Third, the uPA expression profiles pertaining to numerous rare types of NSCLC, including squamous carcinoma, sarcomatoid carcinoma, carcinoid, and unclassified cancer types, are currently unknown. Thus, further clinical trials are required before these forms of cancer can be optimally evaluated. Fourth, the potential confounding variables in each individual study were unable to be assessed. For example, certain studies may have evaluated a combination of various histological types of NSCLC; alternatively, the methods used for the evaluation

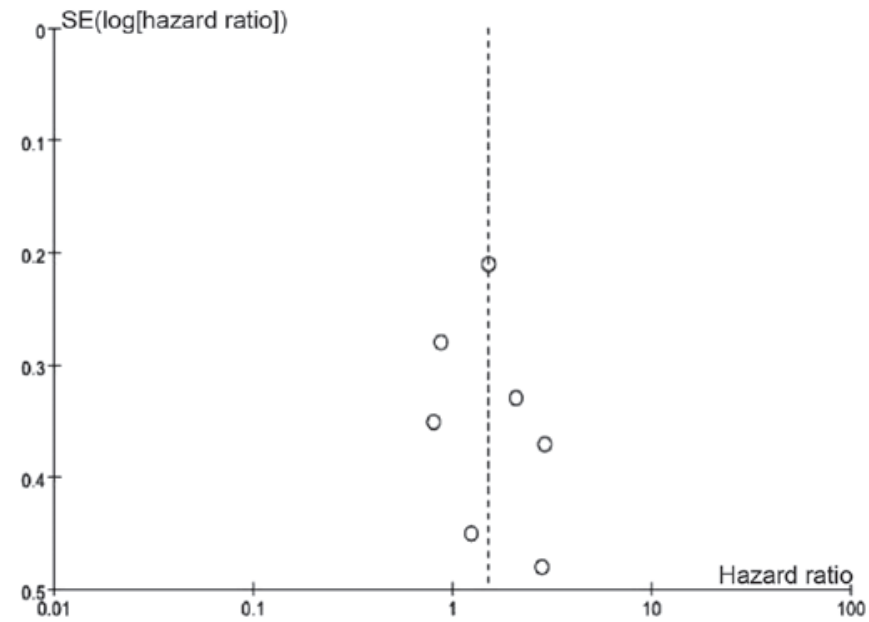

Figure 6. Publication bias of uPAR (Funnel plot). uPAR, urokinase plasminogen activator receptor.

of UPAR expression and differences pertaining to the cutoff (detailed data are not listed) may have differed between studies. Fifth, certain studies could not be included in the meta-analysis owing to the lack of detailed data; sixth, the varied locations and ethnicities may have also contributed to hidden bias.

In conclusion, the present meta-analysis demonstrated that UPAR is associated with the poor prognosis of NSCLC. Thus, UPAR can be used as a biomarker for determining the prognosis of NSCLC, and may assist clinicians in selecting and applying more effective strategies for the treatment of patients with NSCLC. 


\section{References}

1. Torre LA, Bray F, Siegel RL, Ferlay J, Lortet-Tieulent J and Jemal A: Global cancer statistics, 2012. CA Cancer J Clin 65: 87-108, 2015.

2. Chen W, Zheng R, Baade PD, Zhang S, Zeng H, Bray F, Jemal A, Yu XQ and He J: Cancer statistics in China, 2015. CA Cancer J Clin 66: 115-132, 2016.

3. Ben Amar J, Ben Safta B, Zaibi H, Dhahri B, Baccar MA and Azzabi S: Prognostic factors of advanced stage non-small-cell lung cancer. Tunis Med 94: 360-367, 2016.

4. Zhang T, Yu TT, Zhang DM, Hou XM, Liu XJ, Zhao D and Shan L: Vasohibin-1 expression detected by immunohistochemistry correlates with prognosis in non-small cell lung cancer. Med Oncol 31: 963, 2014.

5. Bice T, Li G, Malinchoc M, Lee AS and Gajic O: Incidence and risk factors of recurrent acute lung injury. Crit Care Med 39: 1069-1073, 2011.

6. Rubenfeld GD, Caldwell E, Peabody E, Weaver J, Martin DP, Neff M, Stern EJ and Hudson LD: Incidence and outcomes of acute lung injury. N Engl J Med 353: 1685-1693, 2005.

7. Matthay MA, Robriquet L and Fang X: Alveolar epithelium: Role in lung fluid balance and acute lung injury. Proc Am Thorac Soc 2: 206-213, 2005.

8. Smith HW and Marshall CJ: Regulation of cell signalling by uPAR. Nat Rev Mol Cell Biol 11: 23-36, 2010.

9. Feng MY, Liao QJ and Su Q: Advance in research on uPAR and tumor. Int J Pathol Clin Med 31: 49-53, 2011 (In Chinese).

10. Andres SA, Edwards AB and Wittliff JL: Expression of urokinase-type plasminogen activator (uPA), its receptor (uPAR), and inhibitor (PAI-1) in human breast carcinomas and their clinical relevance. J Clin Lab Anal 26: 93-103, 2012.

11. Thummarati P, Wijitburaphat S, Prasopthum A, Menakongka A, Sripa B, Tohtong $\mathrm{R}$ and Suthiphongchai T: High level of urokinase plasminogen activator contributes to cholangiocarcinoma invasion and metastasis. World J Gastroenterol 18 : 244-250, 2012

12. Urban $\mathrm{P}$, Vuaroqueaux $\mathrm{V}$, Labuhn $\mathrm{M}$, Delorenzi $\mathrm{M}$, Wirapati P, Wight E, Senn HJ, Benz C, Eppenberger U and Eppenberger-Castori S: Increased expression of urokinase-type plasminogen activator mRNA determines adverse prognosis in ErbB2-positive primary breast cancer. J Clin Oncol 24 4245-4253, 2006.

13. Mekkawy AH, Morris DL and Pourgholami MH: HAX1 augments cell proliferation, migration, adhesion, and invasion induced by urokinase-type plasminogen activator receptor. J Oncol 2012: 950749, 2012.

14. Tierney JF, Stewart LA, Ghersi D, Burdett S and Sydes MR: Practical methods for incorporating summary time-to-event data into meta-analysis. Trials 8: 16, 2007.

15. Guyot P, Ades AE, Ouwens MJ and Welton NJ: Enhanced secondary analysis of survival data: Reconstructing the data from published Kaplan-Meier survival curves. BMC Med Res Methodol 12: 9, 2012.

16. Panic N, Leoncini E, de Belvis G, Ricciardi W and Boccia S: Evaluation of the endorsement of the preferred reporting items for systematic reviews and meta-analysis (PRISMA) statement on the quality of published systematic review and meta-analyses PLoS One 8: e83138, 2013.

17. Almasi CE, Høyer-Hansen G, Christensen IJ, Dan $\varnothing \mathrm{K}$ and Pappot H: Prognostic impact of liberated domain I of the urokinase plasminogen activator receptor in squamous cell lung cancer tissue. Lung Cancer 48: 349-355, 2005.

18. Almasi CE, Høyer-Hansen G, Christensen IJ and Pappot H: Prognostic significance of urokinase plasminogen activator receptor and its cleaved forms in blood from patients with non-small cell lung cancer. APMIS 117: 755-761, 2009.

19. Almasi CE, Christensen IJ, Høyer-Hansen G, Danø K, Pappot H, Dienemann $\mathrm{H}$ and Muley T: Urokinase receptor forms in serum from non-small cell lung cancer patients: Relation to prognosis. Lung Cancer 74: 510-515, 2011.

20. Blumenschein GR Jr, Reck M, Fossella F, Stewart DJ, Lathia C and Peña C: Plasma biomarkers correlating with clinical outcome in a phase II study of sorafenib in advanced NSCLC. Cancer Biomark 10: 287-298, 2011-2012.
21. Su CY, Liu YP, Yang CJ, Lin YF, Chiou J, Chi LH, Lee JJ, Wu AT, Lu PJ, Huang MS and Hsiao M: Plasminogen activator inhibitor-2 plays a leading prognostic role among protease families in non-small cell lung cancer. PLoS One 10: e0133411, 2015.

22. Pappot $\mathrm{H}$ : The plasminogen activation system in lung cancer-with special reference to the prognostic role in "non-small cell lung cancer'. APMIS Suppl 92: 1-29, 1999.

23. Offersen BV, Pfeiffer P, Andreasen P and Overgaard J: Urokinase plasminogen activator and plasminogen activator inhibitor type-1 in nonsmall-cell lung cancer: Relation to prognosis and angiogenesis. Lung Cancer 56: 43-50, 2007.

24. Pappot H, Pedersen AN, Brünner N and Christensen IJ: The complex between urokinase (uPA) and its type-1 inhibitor (PAI-1) in pulmonary adenocarcinoma: Relation to prognosis. Lung Cancer 51: 193-200, 2006.

25. Pedersen H, Grøndahl-Hansen J, Francis D, Osterlind K, Hansen HH, Danø K and Brünner N: Urokinase and plasminogen activator inhibitor type 1 in pulmonary adenocarcinoma. Cancer Res 54: 120-123, 1994.

26. Salden M, Splinter TA, Peters HA, Look MP, Timmermans M, van Meerbeeck JP and Foekens JA: The urokinase-type plasminogen activator system in resected non-small-cell lung cancer. Rotterdam Oncology Thoracic Study Group. Ann Oncol 11: 327-332, 2000

27. Werle B, Kotzsch M, Lah TT, Kos J, Gabrijelcic-Geiger D, Spiess E, Schirren J, Ebert W, Fiehn W, Luther T, et al: Cathepsin $\mathrm{B}$, plasminogenactivator-inhibitor (PAI-1) and plasminogenactivator-receptor ( $\mathrm{UPAR}$ ) are prognostic factors for patients with non-small cell lung cancer. Anticancer Res 24: 4147-4161, 2004.

28. Li Y, Shen Y, Miao Y, Luan Y, Sun B and Qiu X: Co-expression of UPAR and CXCR4 promotes tumor growth and metastasis in small cell lung cancer. Int J Clin Exp Pathol 7: 3771-3780, 2014.

29. Thielemann A, Baszczuk A, Kopczyński P and Kopczyński Z: High concentration of urokinase-type plasminogen activator receptor in the serum of women with primary breast cancer. Contemp Oncol (Pozn) 17: 440-445, 2013.

30. Pulukuri SM, Gorantla B, Dasari VR, Gondi CS and Rao JS: Epigenetic upregulation of urokinase plasminogen activator promotes the tropism of mesenchymal stem cells for tumor cells. Mol Cancer Res 8: 1074-1083, 2010.

31. de Bock CE and Wang Y: Clinical significance of urokinase-type plasminogen activator receptor (UPAR) expression in cancer. Med Res Rev 24: 13-39, 2004.

32. Chiang SP, Cabrera RM and Segall JE: Tumor cell intravasation. Am J Physiol Cell Physiol 311: C1-C14, 2016

33. Noh H, Hong $\mathrm{S}$ and Huang S: Role of urokinase receptor in tumor progression and development. Theranostics 3: 487-495, 2013.

34. Montuori N, Pesapane A, Rossi FW, Giudice V, De Paulis A, Selleri $\mathrm{C}$ and Ragno P: Urokinase type plasminogen activator receptor (uPAR) as a new therapeutic target in cancer. Transl Med UniSa 15: 15-21, 2016. 